\title{
Simulations of Frictional Losses in a Turbulent Blood Flow Using Three Rheological Models
}

\author{
ARTUR BARTOSIK \\ Faculty of Management and Computer Modelling \\ Kielce University of Technology \\ Al. Tysiaclecia P.P. 7, 25-314 Kielce \\ POLAND
}

\begin{abstract}
Blood flow rate is a crucial factor in transporting an oxygen and depends on several parameters like heart pressure, blood properties like d ensity and vi scosity, frictional loss an d diameter and shape of vein. Frictional loss is a main challenge of current engin eering. Therefore, sim ulation of dep endence of blood properties on frictional loss is very important. When blood properties are considered the first step is to find proper rheological model. It is well kno wn that human blood demonstrates a yield shear stress. Therefore, the research is focused on simulating frictional losses in a turbulent flow of hu man blood, which dem onstrates a yield stress. Three arbitra rily chosen rheological models were considered, namely Bingham, Casson and Herschel-Bulkley. Governing equations describing turbulent blood flow were developed to axially symmetrical an aorta. The mathe matical model constitutes three partial differential equations, namely momentum equation, kinetic energy of turbulence and its dissipation rate. The main objective of the research is examining influence of the y ield shear stress on frictional losses in a h uman blood in an aorta when flow b ecomes turbulent. Simulation of blood flow confirm ed marginal influence of a yield shear stress on frictional losses when flow becomes turbulent. Results of simulations are discussed and final conclusions are stated.
\end{abstract}

Key-Words: - Turbulent blood flow; simulation of frictional loss; blood yield shear stress

Received: November 15, 2019. Revised: April 30, 2020. Accepted: May 9, 2020. Published: May 21, 2020.

\section{Introduction}

Simulation of blood $\mathrm{fl}$ ow rate is great challenge of fluid mechanics and biomechanics. Blood flow rate is a cruci al factor in tra nsporting an oxy gen and depends on several parameters like he art pressure, blood properties like density and viscosity, frictional loss and diameter and shape of vein. Decreasing the frictional loss is a challeng e of current e ngineering. We can decrease frictional loss using chemical or mechanical techniques. Chemical techniques include medications, which decreas e ablood viscosity or act as defloc culant, while mechanical techniques can use stands in order to increase a vein diameter. The process of blood flow is extremely complex because flowi ng medium and its environment are very complex. Blood is not a liquid with uniform properties causing that interactions between cells and betwee $\mathrm{n}$ cells and veins depend on many factors, mainly including blood flow rate, veins dimension and concentration of hematocrit [1-5]. Blood is a special liqui $\mathrm{d}$ which contains about $55 \%$ of plasma and about $45 \%$ of cells. The plasma exists in close vicinity of a vein wall and contains about $90 \%$ of water and $10 \%$ of proteins, metabolites and ions. Dens ity of plasma is about $1025 \mathrm{~kg} / \mathrm{m}^{3}$. Cells, which constitute about $45 \%$ of blood, are more complex. We recognize three ty pes of cells, as: red cells, white cells, and platelets.
Density of blood cells is about $1125 \mathrm{~kg} / \mathrm{m}^{3}$. Density of blood is about $1060 \mathrm{~kg} / \mathrm{m}^{3}$ [6].

Simulation of a blood flow is extremely difficult, as red blood cells are deformable, have a complex shape, and play a leading role in blood rheology in contrast to white ce lls and platelets [7]. Concentration of red blood cells, called also hematocrit, has a substantial influence on blood flow phenomena together with plasm a film [8]. As the phenomenon of blood flow is very complex, we can find different approaches in literature concerning development of mathematical models. Some of them treat a blood as Newto nian liquid [9] or as mixture of liquid and tissue (cells). Apart from that, we can treat red blood cells as flexible or no nflexible solid bodies. If we consider methods of blood flow modelling, we can recognize meso- and macroscopic approaches, as microscopic modelling refers to the scale of single ato $\mathrm{ms}$ and molecules. If a blood flow environment is taken into account, we know that a constitutive model is effective at describing the anisotropic mechanical response of artery walls.

Literature review indicates that majority of mathematical approaches regard laminar flow, which is rather easy to modelling compared to a turbulent flow. Considering sim ulations of blood flow in micro channels at low and hi gh 
concentrations of hematocrit one can mention the research of Fedosov et al. [2 ] McWhirter et al. [3],[4], Freund and Orescanin [ 5], Peng et al. [10], Dupin et al. [11], Doddi and Bagchi [ 12], and Krüger et al. [13]. However, their m odels deal with laminar blood flow. Therefore, this paper presents a mathematical model, which assumes that blood flow is turbulent, and the maxim um Reynolds number does not exceed 5000. The mathematical model consists of averaged Navier-Stokes equations

(RANS) and a turbulent stress tensor w as calculated using the indirect method, which takes into account the Boussinesque hypothesis [14]. Such hypothesis utilizes turbulent viscosity, which is cal culated based on the chosen two-equation turbulence model.

The main objective of the research is examining dependence of the yield shear stress on frictional losses in human blood in an aorta when flow becomes turbulent.

The friction factor is a cruci al parameter determining the resistance of blood flow in a vein or an aorta. The friction factor effects on frictional losses in a bl ood flow. Frictional losses depend on friction factor, bloo d density and viscosity, bl ood velocity and an aorta dia meter. Therefore, atherosclerosis is a major cause of human mortality caused by decreasing cro ss section of blood flo w and is localized mainly in aorta or middle-sized veins [15]. Higher friction factor causes higher flow resistance resulting in decreasing transport of oxygen. Taking into account the mathematical model of turbulent blood flow in the aorta, influence of a y ield shear stre ss on the friction factor and frictional losses are examined.

\section{Validation of Rheological Models}

Wells and Merrill's experimental data were chosen, which presenter dependence of share $r$ ate on shear stress in human blood for concentration of hematocrit equal to $43 \%$ by volume [10]. Experimental data wer e used to validate three arbitrarily chosen rheological $\mathrm{m}$ odels, namely Bingham, Casson and Herschel- Bulkley. All rheological models were chosen arbitrarily and are described by equations (1), (2) and (3), respectively.

- The Bingham model [16]:

$$
\tau=\tau_{o}+\mu_{P L} \gamma
$$

- The Casson model [17]:

$$
\tau^{1 / 2}=\tau_{o}^{1 / 2}+\left(\mu_{\infty} \gamma\right)^{1 / 2}
$$

- The Herschel-Bulkley model [18]:

$$
\tau=\tau_{o}+K \gamma^{n}
$$

Taking into account $t$ he apparent viscosity concept, one can deter mine the shear stress for a Newtonian liquid, as follows:

$$
\tau=\mu_{\text {app }} \gamma
$$

The apparent viscosity concept means that for shear thinning blo od, the apparent viscosit $y$ decreases as the shear rate increase s [9], [19]. The apparent viscosity depends on $r$ heological model therefore such viscosity will be developed for each of three rhe ological models. Taking i nto account equations (1) and (4), one can develop the equation for apparent viscosity using Binghm model, as follows:

$$
\mu_{a p p}=\frac{\tau_{o}}{\gamma}+\mu_{P L}
$$

In an analog ous way it is shown that the apparent viscosity for Casson and Her schel-Bulkley rheological models can be presented res pectively, as follows [20]:

$$
\begin{aligned}
& \mu_{\text {app }}=\frac{\mu_{\infty}}{\left[1-\left(\frac{\tau_{o}}{\tau_{w}}\right)^{1 / 2}\right]^{2}}=\left[\left(\frac{\tau_{o}}{\gamma}\right)^{1 / 2}+\mu_{\infty}^{1 / 2}\right]^{2} \\
& \mu_{\text {app }}=\frac{\tau_{o}}{\gamma}+K \gamma^{n-1}
\end{aligned}
$$

Validation of the aforementioned rheological models has been performed for hum an blood data reported by Wells and Merrill's containing $43 \%$ of hematocrit with a density of $1060 \mathrm{~kg} / \mathrm{m}^{3}$ at a temperature of $37 \quad{ }^{\circ} \mathrm{C} \quad$ [21]. The following rheological parameters were obtained based on the best fitting $\mathrm{s}$ hear stresses measur ed and calculated using the above rheological models:

- The Bingham model, described by equation (1): $\tau_{0}=0.0588[\mathrm{~Pa}] ; \mu_{\mathrm{PL}}=0.00584[\mathrm{~Pa} \mathrm{~s}] ;$

- The Casson model, described by equation (2): $\tau_{0}=0.0144[\mathrm{~Pa}] ; \mu_{\infty}=0.0046[\mathrm{~Pa} \mathrm{~s}] ;$

- The Herschel-Bulkley model, described b y equation (3):

$\tau_{0}=0.0144[\mathrm{~Pa}] ; \mathrm{K}=0.020\left[\mathrm{~Pa} \mathrm{~s}{ }^{\mathrm{n}}\right] ; \mathrm{n}=0.75$;

Experimental data of Wells and Merrill's presented in Fig.1 dem onstrate the dependence of the shear rate on the shear stress of hum an blood, which contains $43 \%$ of he matocrit [21]. The Casson and Herschel-Bulk ley rheological models, described by equations (2) and (3), provided similar results of sim ulated shear stresses of hum an blood, which is presented in Fig.1. Both $\mathrm{m}$ odels demonstrate tremendous increase of blood viscosity at low shear rates in contrast to the Bingha $\mathrm{m}$ model. The Bingha $\mathrm{m}$ model presents signifi cant simplification of 
predicted shear stresses comparing to measurements, which is seen mainly in Fig.1.

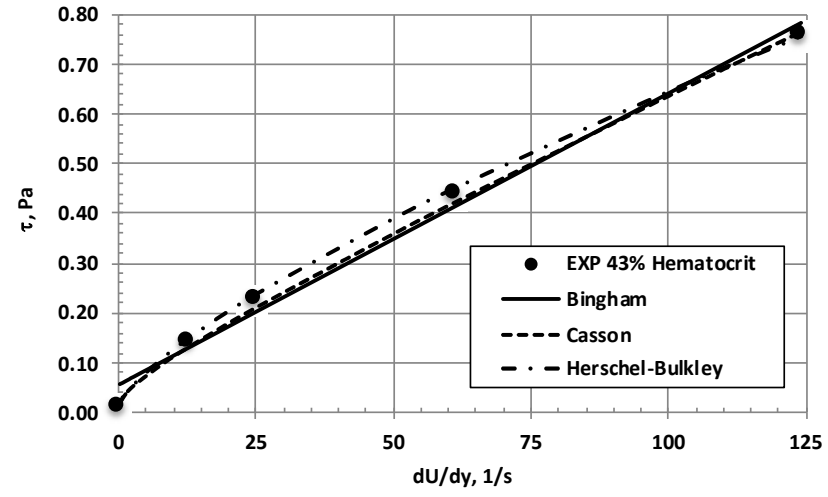

Fig.1 Wells' and Merrill's experiments compared with calculated wall shear stresses in human blood containing $43 \%$ of hematocrit.

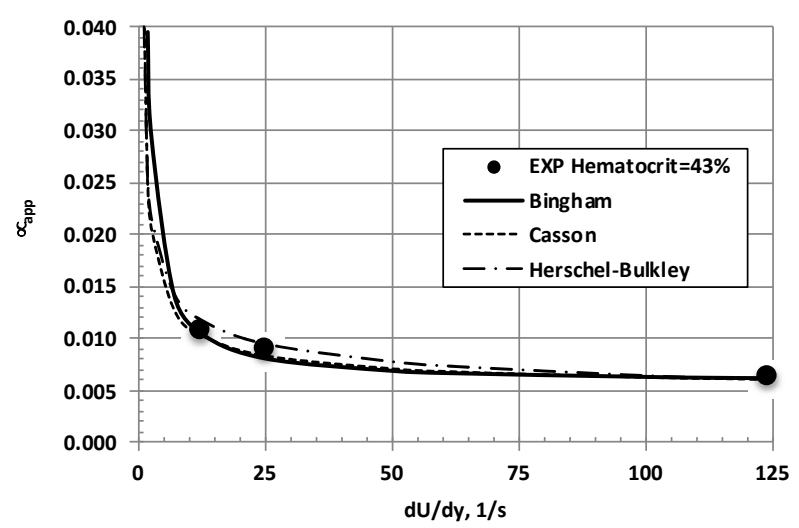

Fig.2 Measured and predicted apparent viscosity of human blood containing $43 \%$ of hematocrit.

Apparent viscosity of human blood calculated on the base of experimental data of Wells and Merrill [21] and results of simulations using equations (5), (6) and (7), which correspond to Bingham, Casson and Herschel-Bulkley rheological models, are presented in Fig.2. It is seen that all rheological models give al most the sa me results for high shear rates. For low shear rate s, however, the Casson and Herschel-Bulkley models demonstrate small advantage comparing to Bingham model.

Concluding, one can say that two rheological models, namely Casson and Hers chel-Bulkley, predict fairly well shear stresses and viscosity of human blood, however, the Herschel-Bulkley model seems to be slightly better co mparing to the Casson model. It is s een that differences betw een results of calculations using three rheological models are not substantial. It is not ve ry crucial which model is most suitable to predict the apparent vi scosity. The apparent viscosity will be used in a momentum equation for a blood $\mathrm{fl}$ ow. The crucial point is developing mathematical model in whic $h$ constitutive equations will take into account complex nature of a bl ood flow, especially when flow becomes turbulent. In further step s the Casson rheological model will be used, as si mpler one comparing to Herschel-Bu lkley model, and $\mathrm{m}$ uch adequate than the Bingham model.

\section{Physical and Mathematical Models}

The physical model assumes that human blood has a yield shear stress, which is in line with the aforementioned experiments of Wells and Merrill [21]. It is well known that transport of oxygen is strictly related to a bl ood flow rate, while blood flow rate depends on frictional losses, which depend on friction factor. For this reason, the resear ch is focused on the influence of blood yield shear stress on the friction factor and the frictional losses when flow becomes turbulent. Looking for simplicity of the physical model, it is assu med that the blood is flowing in a rigid, sm ooth and horizontal aorta of constant diameter and the flow is full y developed, axially symmetrical, turbulent and hom ogeneous. It is also ass umed that the flow is stationary Therefore, the blood is $t$ reated as a single-phase liquid with i ncreased density and vis cosity. The blood has a constant temperature equal to $37^{\circ} \mathrm{C}$.

In order to develop $\mathrm{m}$ athematical model of a turbulent blood flow, the starting point are the timeaveraged Navier-Stokes equations, continuity equation and boundary conditions. In order to build the mathematical model, the Random Averaged Navier-Stokes approach (RANS) has been used.

Taking into account the aforem entioned assumptions, the co ntinuity equation of incompressible blood flow can be described in the following form:

$$
\frac{\partial \bar{U}}{\partial x}=0
$$

while the momentum equation consists of th $\mathrm{e}$ Random Averaged Navier-Stokes equation, the final form of which for the afore mentioned assumptions in cylindrical coordinates is as follows:

$$
\frac{1}{r} \frac{\partial}{\partial r}\left[r\left(\mu_{\text {app }} \frac{\partial \bar{U}}{\partial r}-\bar{\rho} \overline{u^{\prime} v^{\prime}}\right)\right]=\frac{\partial \bar{p}}{\partial x}
$$

where the upper dash means the time averaged quantity.

The component of turbulent stress tensor, which appears in equation (9), can be designated throug $h$ an indirect method using the Boussinesque hypothesis, as follows [14]:

$$
-\bar{\rho} \overline{u^{\prime} v^{\prime}}=\mu_{t} \frac{\partial \bar{U}}{\partial r}
$$


Several turbulence models are available in literature, which $\mathrm{m}$ ake it possible to describe the turbulent stress tensor. In this research, the Launder and Sharma turbulence model was use $d$ [22]. This particular turbulence model has a great capacity for predicting solid-liquid flows [23]. The Launder and Sharma turbulence model assumes that the turbulent viscosity, which appears in equation ( 10$)$, can be designated using dimensionless analysis, as follows [22]:

$$
\mu_{t}=f_{\mu} \frac{\bar{\rho}}{\varepsilon} k^{2}
$$

where the kinetic energy of turbulence and its dissipation rate are derived from Navier-Stokes equations using the time-average procedure and are as follows:

- The kinetic energy of turbulence:

$$
\begin{aligned}
& \frac{1}{r}\left[r\left(\mu_{\text {app }}+\frac{\mu_{t}}{\sigma_{k}}\right) \frac{\partial k}{\partial r}\right]+\mu_{t}\left(\frac{\partial \bar{U}}{\partial r}\right)^{2} \\
= & \bar{\rho} \varepsilon+2 \mu_{\text {app }}\left(\frac{\partial k^{1 / 2}}{\partial r}\right)
\end{aligned}
$$

- The rate of dissipation of the kinetic energ y of turbulence:

$$
\begin{array}{r}
\frac{1}{r}\left[r\left(\mu_{a p p}+\frac{\mu_{t}}{\sigma_{\varepsilon}}\right) \frac{\partial \varepsilon}{\partial r}\right]+C_{1} \frac{\varepsilon}{k} \mu_{t}\left(\frac{\partial \bar{U}}{\partial r}\right)^{2}= \\
C_{2}\left[1-0.3 \exp \left(-R e_{t}^{2}\right)\right] \frac{\bar{\rho} \varepsilon^{2}}{k}-2 \frac{\mu_{a p p}}{\bar{\rho}} \mu_{t}\left(\frac{\partial^{2} \bar{U}}{\partial r^{2}}\right)
\end{array}
$$

The turbulence damping function $\left(f_{\mu}\right)$ in equation (11) and the turbulent Reynolds number in equation (13) were defined b y Launder and Sharm a in the turbulence model [22], as follows:

$$
\begin{gathered}
f_{\mu}=0.09 \exp \left[\frac{-3.4}{\left(1+\frac{R e t}{50}\right)^{2}}\right] \\
R e_{t}=\frac{\bar{\rho}}{\varepsilon} \frac{k^{2}}{\mu_{\text {app }}}
\end{gathered}
$$

The mathematical model of turbulent human blood flow in an aorta consists three partial differential equations (9), (12) and (13) together with complimentary equations $(6),(10),(11),(14)$ and (15). The model assumes non slip velocity at the aorta wall. The boundary conditions at the aorta wall assume that $\mathrm{U}=0, \mathrm{k}=0$ and $\varepsilon=0$, while in symmetry axis it is assumed that $\partial \mathrm{U} / \partial \mathrm{r}=0, \partial \mathrm{k} / \partial \mathrm{r}=0$, $\partial \varepsilon / \partial \mathrm{r}=0$. Constants in the Launder and Sharma turbulence model are the sa me like for Newtonian flow and are following: $\mathrm{C}_{1}=1.44 ; \mathrm{C}_{2}=1.92 ; \sigma_{\mathrm{k}}=1.0$; $\sigma_{\varepsilon}=1.3$ [22]. The $\mathrm{m}$ athematical model has been solved for 80 nodal points not uniformly distributed on the aorta radius $\mathrm{R}=0.004[\mathrm{~m}]$. Most of the nodal points were localized in close vicinity of the aorta wall with expansion coefficient equal to 1.10 . The number of nodal points was set experim entally to provide nodally independent simulations. Computations were made using own computer code [22]. The set of partial differential eq uations (9), (12) and (13) were solved b y taking into account TDMA approach, with it eration procedure, usin $g$ control volume method [24]. Iteration cy cles were repeated until criterion of convergence, defined by equation (16), was achieved.

$$
\sum_{j}\left|\frac{\phi_{j}^{n}-\emptyset_{j}^{n-1}}{\emptyset_{j}^{n}}\right| \leq 0.0005
$$

The $\emptyset_{j}^{n}$ is the value of $\emptyset$ at the $\mathrm{j}^{\text {th }}$ grid node after the $\mathrm{n}^{\text {th }}$ iteration cycle while $\emptyset_{j}^{n-1}$ is for the $(\mathrm{n}-1)^{\text {th }}$ iteration cycle.

\section{Results of Simulations}

The yield shear stress of human blood is a $n$ indicator of cells aggregation. The yield shear stress of a hu man blood describes a critical stress below which no flow takes place. S everal researchers confirmed the importance of the yield shear stress in a flow. So me of them explained of its nature.

Michaels and Bolger provided a com prehensive explanation of phenomenon of yield shear stress [25], [26]. They reasoned that a y ield shear stress has two components: a true network strength, which must be overcome for motion to occur at all, and a creep energy dissipation effect accompanying the collisions between flocs. They conside red the flocs to be the basic unit of the suspension and that aggregates of flocs formed at low shear rates. The flocs were smaller than the aggregate $s$ and shear tends to produce more dense flocs. If the blood flow rate in the aorta starts fro $\mathrm{m}$ zero and i s increasing, we go throu gh regimes of lam inar, transient and turbulent flow.

Non-Newtonian behavior of a blood flow indicates that changes of wall shear stress resulting in changes of apparent viscosity, which is expres sed by equation (6). Fig.3 presents calculated apparent viscosity using Casson model for different wall shear stress in the range from 5 to $50 \mathrm{~Pa}$ for hum an blood flow containing $43 \%$ of hem atocrit. In the range of wall shear stres $\mathrm{s}$ from 5 to $50[\mathrm{~Pa}]$ there exists laminar, transient and turbulent flow in the aorta with a radius of $\mathrm{R}=0.004[\mathrm{~m}]$. For example, if the wall sh ear stress equals $\tau_{\mathrm{w}}=30 \quad[\mathrm{~Pa}]$, the Reynolds number, defined b y equation (17), is $\mathrm{Re}=4000$, which means that blood flow for $\tau_{\mathrm{w}} \geq 30$ $\mathrm{Pa}$ is fully turbulent. 


$$
\operatorname{Re}_{\mathrm{ap}}=\frac{\rho_{\mathrm{b}} \mathrm{U}_{\mathrm{b}} \mathrm{D}}{\mu_{\mathrm{app}}}
$$

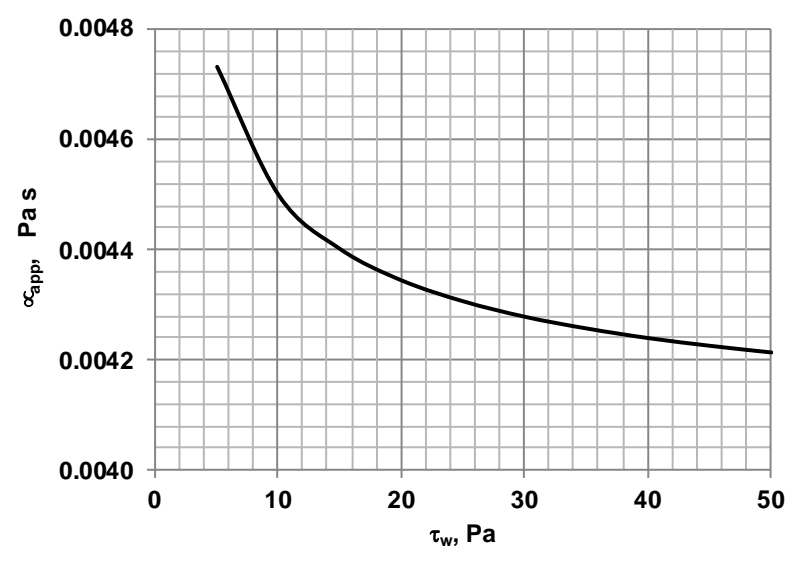

Fig.3 Simulation of the influence of human blood shear stress at the aorta wall containing $43 \%$ of hematocrit, on apparent viscosity.

After analyzing equation (6) and Fig.3, one can say that influence of the yield shear stress on the apparent viscosity of human blood inc reases when the wall shear stress decreases. It is well known that in laminar flow, the w all shear stress is low compared to a turbulent one. In order to demonstrate this phenomenon, simulation of the influence of the yield shear stress on the apparent viscosity of human blood for different values of wall shear stresses was made, which is presented in Fig.4. As an exa mple, let us assu me that the y ield shear str ess equals $\tau_{\mathrm{o}}$ $=0.03[\mathrm{~Pa}]$. In such a c ase, the apparent viscosity of human blood is $\mu_{\text {app }}=0.0047[\mathrm{~Pa} \mathrm{~s}]$ or $\mu_{\mathrm{app}}=0.00418$ [Pa s] depending on the wall shear stress, which is respectively $\tau_{\mathrm{w}}=5[\mathrm{~Pa}]$ and $\tau_{\mathrm{w}}=60[\mathrm{~Pa}]-$ see Fig. 4 . In such a case, decrease of relative apparent viscosity is about $11 \%$. If the wall shear tress equals $\tau_{\mathrm{w}}=5[\mathrm{~Pa}]$ the flow becomes lam inar, while for $\tau_{\mathrm{w}}=60[\mathrm{~Pa}]$, it is turbulent. This clea rly means that the importance of the $y$ ield shear stress in a turbulent blood flow is lower compared to its importance in a laminar flow.

It can be seen in $\mathrm{Fi}$ g.4 that under the laminar flow regime, which exists for the wall shear stress $\tau_{\mathrm{w}}=5[\mathrm{~Pa}]$, the apparent viscosity substantiall $\mathrm{y}$ increases with the yield stress increase. In such a case, for the $y$ ield shear stress $\tau_{0}=0[\mathrm{~Pa}]$, the apparent viscosity equals $\mu_{\text {app }}=0.004[\mathrm{~Pa} \mathrm{~s}]$, while for the y ield shear stress $\tau_{0}=0.05[\mathrm{~Pa}]$, the relative increase of the apparent viscosity is about $23.5 \%$. However, for higher wall shear stre ss than $5 \mathrm{~Pa}$, which is due to transient and turbulent flow regimes, the rate of increase of apparent viscosity drops down, which is seen in Fig.4 for $\tau_{\mathrm{w}}=15 ; 30 ; 60[\mathrm{~Pa}]$. To clarify this, let us consider a blood flow at $\tau_{\mathrm{w}}=30$ $\mathrm{Pa}$, which corresponds to a Rey nolds number of
$\mathrm{Re}=4000$. For such a case, the relative increase of apparent viscosity equals to about $9 \%$ at $\tau_{0}=0.05$ $[\mathrm{Pa}]$, comparing to its value at $\tau_{0}=0[\mathrm{~Pa}]$. This phenomenon is even $\mathrm{m}$ ore pronounced if the wall shear stress equals to $60[\mathrm{~Pa}]$. Concluding, one can say that the influence of the yield shear stress on the apparent viscosity of h uman blood is significant when flow becomes laminar, and is less important in a turbulent flow.

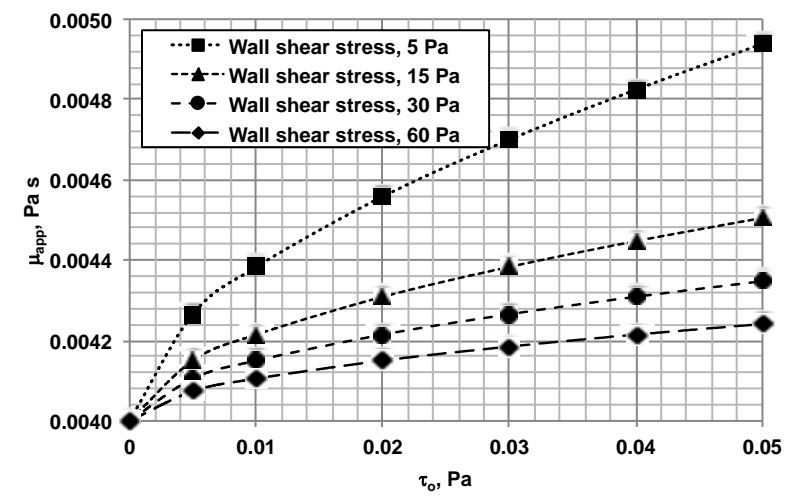

Fig.4 Simulations of the influence of yield shear stress on apparent viscosity in human blood flow containing $43 \%$ of hematocrit for different shear stresses at the aorta wall.

Lee et al. [27] examined two rheological models, namely the Casson and the Herschel-Bulkley models, looking for best fit for the experiments on human blood. They concluded that the yield shear stress value is $\tau_{0}=14.4[\mathrm{mPa}]$ for the Casson model and $\tau_{0}=32.5[\mathrm{mPa}]$ for the Herschel-Bulkley model. Their study showed that the Casson model is more suitable than the Herschel-Bulkley m odel for representing the non-Newtonian characteristics of blood viscosity. Taki ng into account the achievements of Lee at al. [27 ], the numerical simulations of friction $\mathrm{f}$ actor $\lambda$ were performed. Simulations were made for turbulent blood flow in the aorta with a radius $\mathrm{R}=0.004[\mathrm{~m}]$ using Casson rheological model. Two values of y ield shear stresses proposed by Lee at al. [27] were chosen: $\tau_{0}=0.0144[\mathrm{~Pa}]$ and $\tau_{0}=0.0325[\mathrm{~Pa}]$. Of course, the value of the yield shear stress equals $t$ o $\tau_{0}=0.0325$ [Pa] is about $125 \%$ higher than it should be for the Casson model, as Lee at al. [27] concluded. This was made intentionall $\mathrm{y}$ in order to examine importance of the yield shear stress o $n$ the friction factor and the frictional losses. Sim ulations of friction factor $\lambda$ for turbulent blood flow for two different yield shear stresses are presented in Fig.5. Simulations were made for Reynolds numbers from 2900 to 5000 . Results clearly demonstrate there are no differences of friction factor for the two different values of the $y$ ield shear stress ( $\tau_{0}=0.0144$ and $0.0325[\mathrm{~Pa}])$, as both predictions lie on the sam e 
curve. The r esults confirmed that the influence of the yield shear stress on the friction factor in turbulent human blood flow containing $43 \%$ of hematocrit can be neglected.

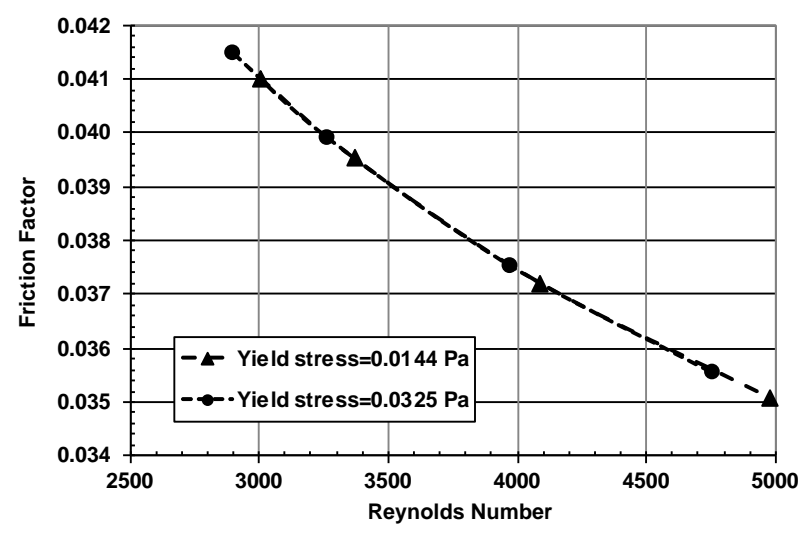

Figure 5. Simulation of the influence of Reynolds number on friction factor for human blood containing $43 \%$ of hematocrit, for two different yield stresses.

Frictional loss is the loss of pressure or "head" that occurs in a pipe or duct flow on length $\mathrm{L}$, due to the effect of the fluid's viscosity near the pipe or duct wall. Considering an aorta of inner diameter $\mathrm{D}$ and length $\mathrm{L}$ the force responsible for a blood flow can be expressed as follows:

$$
F_{1}=\Delta p A=\Delta p \frac{\pi D^{2}}{4}
$$

while the force responsible for a blood resistance is following:

$$
F_{2}=\pi D L \tau_{w}
$$

Considering the equilibrium state, which means that the flow is steady, both forces $F_{1}$ and $F_{2}$ should be equal, therefore the equilibrium equation can be expresses as follows:

$$
\Delta p \frac{\pi D^{2}}{4}=\pi D L \tau_{w}
$$

or in other form as follows:

$$
\frac{\Delta p}{L}=\frac{4 \tau_{w}}{D}
$$

The term $\Delta \mathrm{p} / \mathrm{L}$ is the same as $\mathrm{dp} / \mathrm{dx}$ and is known as frictional loss or pressure gradient and demonstrates pressure losses during a blood flow on length $\mathrm{L}$ or dx.

Simulations of frictional losses for two different yield shear stresse s equal to $\tau_{0}=0.0144$ and 0.0325 $[\mathrm{Pa}]$ and for the range of Rey nolds numbers from 2900 to 5000 are presented in Fig.6. It is seen that results of calculations us ing mathematical model presented by equations (6) and (9) - (15) are al most the same. Results confir med again that the importance of the y ield shear stress in turbulent human blood flow, which contain $43 \%$ of hematocrit is marginal.

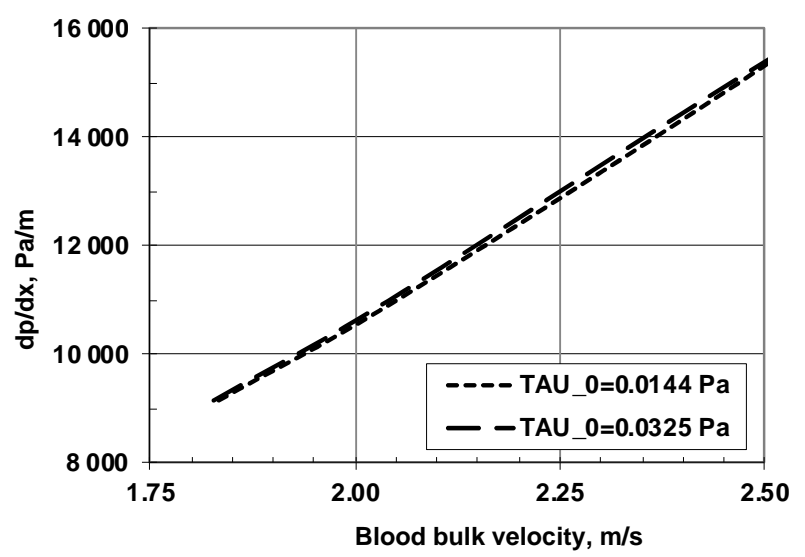

Fig.6 Simulation of the frictional losses for human blood containing $43 \%$ of hematocrit, for two different yield stresses.

\section{Discussion}

When the flow of human blood $\mathrm{i} \quad \mathrm{n}$ an aorta is considered, it is usually assumed that such flow is laminar. However, it is known that under som e circumstances, like phy sical activities, the flow of human blood in an aorta can be turbulent. Of course, the blood $\mathrm{fl}$ ow is pulsating in its $\mathrm{n}$ ature, which means there exist ac celeration and deceler ation phases in a flow. It is well known that during deceleration phase the hu man blood dem onstrates increase of turbulence. This clearly means that if we consider a b lood flow as a lam inar, we should consider that in some short period of a heart beat the flow could be turbulent. Therefore, assuming that a blood flow in an aorta is turbulent, it is interesting to know if blood yield shear stress play s an important role in transporting ox ygen. If the y ield shear stress will decrease the bl ood flow rate the transport of oxygen will be reduced $t$ oo. For this reason, the mathematical model of full $y$ developed and stationary blood flow in the aorta was developed. Of course, the mathematical model is si mplified and does not $t$ ake into account aorta flexibilit $y$, pulsation, and the com plex nature of a blo od, especially that red blood cells are deformable. Individual red blood c ells experience severe deformation and transient folded con formations, which model does not include. Nevertheless, numerical simulations confirmed that under the turbulent regime of a hum an blood flow $t$ he influence of the yield shear stress o $\mathrm{n}$ the blood friction factor is not im portant. This could be in contrast to a lam inar blood flow because analy zing equation (6) and Fig.3, one can say that influence of 
the yield shear stress on the apparent viscosity of human blood increases when the wall shear stress decreases.

Considering rheology of a human blood one can say that Herschel-Bulkley and Casson $m$ odels are fully adequate. Nevertheless, it was proved in Fig.1 and Fig.22 there are not substantial differences between all three chosen rheological models.

We know that viscosity affects shearing stress, which increases blood friction. Higher blood friction results in lower blood flow rate and, as a consequence, lower transportation of oxygen. However, if blood flow beco mes turbulent, the importance of viscosity decreases, as turbulence is a major player affecting blood flow properties. There are two main reasons affecting such behavior of a blood. Firstly, blood yield shear stress is relatively low, especially for low concentration of hematocrit. Secondly, the importance of apparent viscosity in turbulent flow is low, as turbulence plays a crucial role in a blood transportation. If turbule nce is taken into consideration, the turbulent viscosity, described by equation (11), plays dominant role. Taking into account Fig.3 and Fig.4 it is clear that as the wall shear stress increases, the blood apparent viscosity decreases. However, if the yield stress increases, the apparent viscosity increas es too (assu ming that the wall shear stress is constant). In conclusion, one can say that the wall shear stress and the yield shear stress affect blood appa rent viscosity oppositely . Fig.5 and F ig. 6 explicitly show that the blood friction factor and the frictional losses lie on the same line for two different yield shear stresses equal to $14.4[\mathrm{mPa}]$ and $32.5[\mathrm{mPa}$. The presented results confirmed that if turbulent hum an blood flow is taken into consideration, the importance of the yield shear stress is marginal.

The research was carried out for human blood containing $43 \%$ of hematocrit. We can anticipate that for lower concentrat ions of hematocrit, the influence of the y ield shear stre sses on the human blood friction factor can be neglected to o. However, for concentration of hematocrit higher than $43 \%$, it is difficult to anticipate if the influence of the y ield shear stress on the friction factor and the frictional losses is st ill marginal. Such simulations are important if the influence of medications on bl ood flow transportation, for known concentration of hematocrit, are considered.

\section{Conclusions}

On the base of numerical simulations, it is possible to formulate following conclusions:
1. All three rheological m odels, namely Bingham, Casson and Herschel -Bulkley, describing dependence of the shear rate on the she ar stress, give similar results when hum an blood is considered. Nevertheless, the Casson m odel, which is sim pler comparing to the HerschelBulkley model, and $\mathrm{m}$ ore accurate than the Bingham one, seems to be adequate to describe human blood rheology.

2. There is no influence of the yield shear stress on the friction $\mathrm{f}$ actor in a turbulent $\mathrm{h}$ uman blood flow.

3. Influence of the yield shear stress on the frictional losses in a turbulent human blood flow is marginal.

4. When human blood flow becomes turbulent the influence of the yield shear stress on the apparent viscosity is marginal. $\mathrm{H}$ owever, when a flow becomes laminar the i mportance of the y ield shear stress should not be marginalized.

\section{Nomenclature:}

$$
\begin{aligned}
& \text { A } \quad \text { cross section of an aorta }\left[\mathrm{m}^{2}\right] \\
& \mathrm{C}_{\mathrm{i}} \text { - constants in the Launder and Sharma } \\
& \text { turbulence model, } \mathrm{i}=1,2 \\
& \text { D } \quad \text { inner aorta diameter [m] } \\
& \mathrm{f}_{\mu} \quad \text { - turbulence damping function } \\
& \mathrm{F}_{\mathrm{i}} \quad \text { - force acting on a blood [N], i=1, } 2 \\
& \mathrm{j}-\text { number of nodal points } \\
& \mathrm{k}-\text { kinetic energy of turbulence }\left[\mathrm{m}^{2} / \mathrm{s}^{2}\right] \\
& \mathrm{K} \text { - coefficient in the Herschel-Bulkley } \\
& \text { rheological model [ } \left.\mathrm{Pa} \mathrm{s}^{\mathrm{n}}\right] \\
& \mathrm{L} \quad-\text { length of an aorta [m] } \\
& \text { n - power exponent in the Herschel-Bulkley } \\
& \text { rheological model or number of iterations } \\
& \text { cycles } \\
& \mathrm{p} \quad \text { - static pressure }[\mathrm{Pa}] \\
& \mathrm{r} \text { - distance from symmetry axis [m] } \\
& \mathrm{R} \quad \text { - inner aorta radius [m] } \\
& \text { Re - Reynolds number } \\
& \text { u', v' - fluctuating components of blood velocity } \\
& {[\mathrm{m} / \mathrm{s}]} \\
& \mathrm{U} \quad \text { - blood velocity component in direction } \mathrm{x} \\
& {[\mathrm{m} / \mathrm{s}]} \\
& \mathrm{x} \quad \text { - axial coordinate }[\mathrm{m}] \\
& \mathrm{y}-\text { distance from the aorta wall [m] }
\end{aligned}
$$

Greek symbols:

$$
\begin{array}{ll}
\Delta & - \text { difference } \\
\gamma & - \text { shear rate, du/dy (shear deformation rate) } \\
& {[1 / \mathrm{s}]} \\
\Phi & - \text { general dependent variable } \Phi=\mathrm{U}, \mathrm{k}, \mathrm{e} \\
\varepsilon & - \text { rate of dissipation of kinetic energy of }
\end{array}
$$




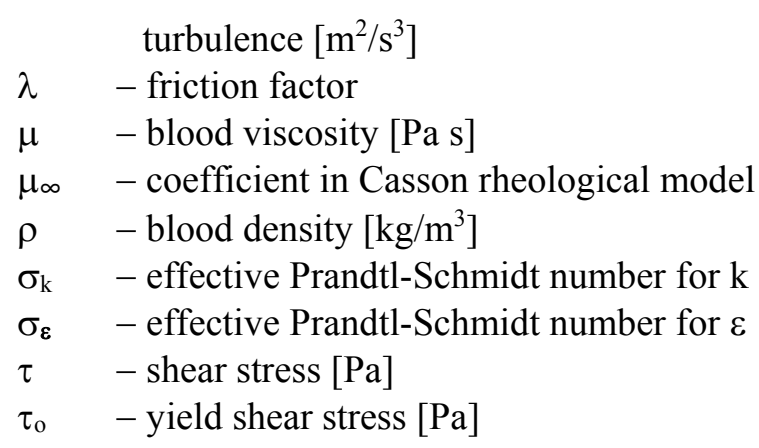

Subscripts:

app - apparent viscosity

b - bulk (cross sectional averaged value)

PL - plastic

t $\quad$ - turbulent

w - wall

\section{References:}

[1] Yilmaz F. and Gundongdu M.Y., A critical review on blood flow in large arteries; relevance to blood rheology, viscosity models, and physiologic conditions, J. Korea-Australia Rheology, Vol.20, 2008, pp.197-211.

[2] Fedosov D.A., Caswell B., Karniadakis G.E., Blood flow and cell-free 1 ayer in microvessels, Microcirculation, Vol.17, 2010, pp.615-628.

[3] McWhirter J.L., Noguchi H., Go mpper G., Flow-induced clustering and alig nment of vesicles and red blood cells in m icrocapillaries, Proc. Natl. Acad. Sci. USA, Ed. Nelsen D.R., Harvard University Cambridg, Vol.106, No.15, 2009, pp.6039-6043.

[4] McWhirter J.L., Noguchi H., Go mpper G., Deformation and clustering of red blood cells in microcapillary flows, Soft Matter, Vol. 7, 2011, pp.10967-10977.

[5] Freund J.B. and Orescanin M.M., Cellular flow in a small blood vessel, J. Fluid Mechanics, Vol.671, 2011, pp.466-490.

[6] Cutnell J.D. and Johnson K.W., Physics, 4th Ed., Vol.1, John Wiley \& Sons Inc, 1997.

[7] Merrill E.W., Rheology of blood, Physiological Reviews, Vol.49, No.4, 1969, pp.863-888.

[8] Picart C., Piau J.M., Galliard H., Huma n blood shear yield stress and its hematocrit dependence, J. Rheology, Vol.42, 1998, pp.112.

[9] Evans E. and Yeung A., Apparent viscosity and critical tension of blood granulocytes determined by niscropipet and as piration, Biophyscics Journal, Vol.56, 1989, pp 151160.

[10] Peng S.L., Shih C.T., Huang C.W., C hiu S.C., Shen W.C., Optimized analysis of blood flow and wall shear stress in the comm on carotid artery of rat model by phase-contrast, MRI Scientific Reports, 7:5254, 2017, pp.1-9.

[11] Dupin M.M., Holliday I., Care C.M., Alboul L., Munn L .L., Modeling the flow of dense suspensions of deform able particles i $\mathrm{n}$ three dimensions, Physics Review, E 75(6) 066707, 2007, pp.1-19.

[12] Doddi S.K. and Bagchi P., Three-dim ensional computational modeling of multiple deformable cells flowing in microvessels, Phys. Rev. E 79:046318, 2009, pp.1-9.

[13] Krüger T., Varnik F., Raabe D., Effici ent and accurate simulations of deformable particles immersed in a fluid using a combined immersed boundary lattice Boltzmann finite element method, Computers \& Mathematics with Applications, Vol.61, No.12, 2011, pp.3485-3505.

[14] Boussinesque J, Theorie de l' ecoulement tourbillant, Mem. Acad. Sci., Vol 2 3, 1877, p.46.

[15] Binbin S., Peiyi G., Yan L., Bing G., Long L. and Jing A., Blood flow pattern and wall shear stress in the internal carotid arteries of healthy subjects, Acta Radiologica, Vol.49, No.7, 2008, pp.806-814.

[16] Bingham E.C., Fluidit y and p lasticity, McGraw-Hill, New York, 1922.

[17] Casson N. A flow equation for pi gment-oil suspensions of the printin $\mathrm{g}$ ink type Rheology of Dispersed Systems, London Pergamon Press, 1959, pp.84-104.

[18] Herschel W.H. and Bulkley.R, Measurements of consistancy as applied to rubber- benzen solutions, Proc. ASTM, Vol.26, Part 2, 1926, pp.621-633.

[19] Ferguson J. and Kemblowski Z., Applied Fluid Rheology, Elsevier, London, 1991.

[20] Bartosik A., Sim ulation and Experiments of Axially-symmetrical Flow of Fine- and Coarsedispersive Slurry in Delivery Pipes, Monography M11, Ed. Kielce University of Technology, 2009, p.257.

[21] Wells R.E. and Merrill E.W., Influence of flow properies of blood upon viscosity - hematocrit relationship, J. Clinic Investigation, Vol.41, No.8, 1962, pp.1591-1598.

[22] Launder B.E. and Sharm a B.I., Applic ation of the energy-dissipation model of turbulence to the calculation of flow near a spinning disc, Letters in Heat and Mass Transfer, No.1, 1974, pp.131-138.

[23] Bartosik A., Application of rheological models in prediction of $t$ urbulent slurry flow, Flow, 
Turbulence and Combustion, Vol.84, No.2, 2010, pp.277-293.

[24] Roache P.J., Com putational Fluid D ynamics, Hermosa Publ. Albuquerque, 1982.

[25] Michaels A.S. and Bolge r J.C., Settling rates and sediment volumes of flocculated Kaolin suspensions, J. Industrial \& Engineering Chemistry Fundamentals, Vol 1, No.1, 1962 , pp.24-33.

[26] Michaels A.S. and Bolger J.C., The plastic flow behavior of flocculated Kaolin suspensions, $J$. Industrial \& Engineering Chemistry Fundamentals, Vol.1, No.3, 1962, pp.153-162.

[27] Lee B.K., Xue S., Nam J., Lim H., Shin S., Determination of the blood viscosity and yield stress with a pressure-scanning capillary hemorheometer using constitutive models, Korea-Australia Rheology J., Vol.23, No.1, 2011, pp.1-6. 